\title{
|||||||||||||||||||||||||||||||||||||||||||||||||||||||||||
}

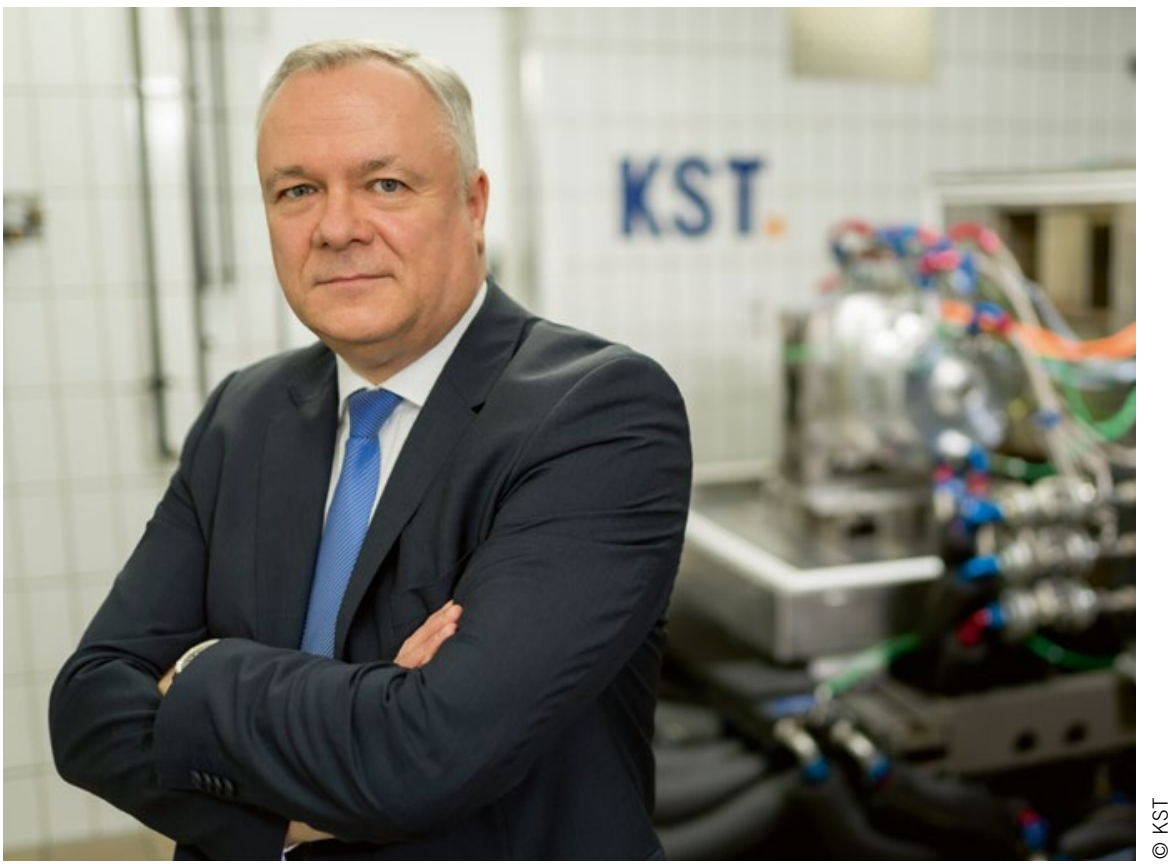

Prof. Dr. Gerhard Reiff

Chairman of the Executive Board, KST-Motorenversuch GmbH \& Co. KG

\section{A Changing Market for Testing Service Providers}

Who will ultimately decide on the end of the internal combustion engine in individual mobility? Will it be the customer, full of enthusiasm for the seamless and overwhelming acceleration of electric motors? Or the established industry, which would like to make a profit from its installed capacities for as long as possible? And we must not forget the oil and gas industry, which, without gasoline and diesel engines, would no longer be able to sell sufficient quantities of certain distillates from its refineries. Or will the future generation of drivers even care about what kind of drive system their car has - as long as it is fully connected and takes them from A to B as autonomously as possible?

A long-established engine testing service provider like KST must learn how to deal with all of these uncertain future scenarios. In the first decades of the company's history, which now spans almost fifty years, it was still relatively easy to meet the demands of the market. Engines became bigger or smaller, but always more efficient - and more complex with regard to their exhaust system and powertrain. But one thing remained the same: cars were still powered by gasoline or diesel.

Then, in the past decade, it became obvious that complexity will increase. At KST too, the focus of investment has shifted towards electric motors and complex powertrains. We must now prepare ourselves for the future. It is not yet foreseeable whether the fuel cell will be the favourite or whether an improved battery will make it superfluous - at least in passenger cars. And the economic and ecological benefits of hybrid drive systems still raise additional unanswered questions, at least for the time being, due to their consumption of primary resources.

A medium-sized company can hardly afford to pursue all trends and to prepare for them with a testing portfolio that is relevant for each individual application. In such cases, a single strategic error will have serious consequences. That applies not only to the purely financial aspects but also in particular to the essentially important human resources. Meeting the requirements of all developments that accumulate at a service provider requires a well-considered strategy for human resources and their development.

But do these exciting events not also open up special opportunities for a testing service provider? The answer must clearly be "yes". It is already the case that there is a clear shift in the development risk for new powertrain technology from OEMs to Tier 1 suppliers. And these, in turn, often shy away from the not inconsiderable investment in new testing expertise. Those service providers who position themselves in this changing value chain with the right sensitivity for the core competences of tomorrow and beyond will stand out above their competitors in the next few decades and will make a positive contribution towards further change in our industry. 